\title{
Characterization of Asian and North American avian H5N1
}

\section{Wei Hu}

Department of Computer Science, Houghton College, New York, USA.

E-mail: wei.hu@houghton.edu

Received 15 March 2011; revised 13 May 2011; accepted 30 May 2011.

\begin{abstract}
Since the emerge of the highly pathogenic avian H5N1 virus in Asia in 1996, the possibility for this virus to cross species barriers to infect humans and its ability to cause large outbreaks in birds have been a public health concern. This virus has been spreading from Asia to Europe and Africa by migratory birds with North America as its next possible stop. In this study, an ensemble of computational techniques including Random Forests, Informational Spectrum Method, Entropy, and Mutual Information were employed to unravel the distinct characteristics of Asian and North American avian H5N1 in comparison with human and swine H5N1. Critical differences were identified in the HA cleavage and binding sites, the $\mathrm{HA}$ receptor selection, the interaction patterns of $\mathrm{HA}$ and NA, and NP, PA, PB1, and PB2, and the important sites in the influenza proteins including $\mathrm{HA}$, NA, M1, M2, NS1, NS2, NP, PA, PB1, PB1-F2, and PB2.
\end{abstract}

Keywords: H5N1; Hemagglutinin, Influenza;

Informational Spectrum Method; Mutation; Random Forests; Receptor Binding Specificity

\section{INTRODUCTION}

Wild birds are a natural reservoir of all known influenza A subtypes, and many of these viruses cause only mild symptoms in birds. The highly pathogenic avian H5N1 virus was first detected in China in 1996 [1] and was also the cause of two subsequent outbreaks in migratory birds at Qinghai Lake in China in 2005 and 2006. The first group of H5N1 human infections were reported in Hong Kong in 1997 [2]. However, there is no evidence of efficient human-to-human transmission of the highly pathogenic avian $\mathrm{H} 5 \mathrm{~N} 1$ virus. This virus has spread to other Asian countries including Indonesia, Japan, Korea, Thailand, Vietnam, and Malaysia, and most recently to Europe and Africa. Therefore, there is a growing concern over the potential for migratory birds to introduce the highly pathogenic Asian H5N1 strain into North America. A strategic plan was developed for the early detection of highly pathogenic avian $\mathrm{H} 5 \mathrm{~N} 1$ in the United States [3].

In addition to the possible spread of highly pathogenic avian $\mathrm{H} 5 \mathrm{~N} 1$ by migratory birds, viral mutations and reassortment of avian, human and swine viruses could generate a new strain capable of transmission among humans. In particular, swine can serve as a "mixing vessel" in the generation of a novel virus, because they are susceptible to infection with both avian and human viruses. A recent report [4] showed that swine H1N1, $\mathrm{H} 1 \mathrm{~N} 2$, and $\mathrm{H} 3 \mathrm{~N} 2$ viruses are currently co-circulating in China, and the highly pathogenic avian $\mathrm{H} 5 \mathrm{~N} 1$ virus might be able to contribute genes to swine $\mathrm{H} 3 \mathrm{~N} 2$ virus, demonstrating the continued risk for further reassortment of swine virus and continued spread of pandemic 2009 H1N1 virus worldwide. Another fear is that if swine can carry both H5N1 and 2009 H1N1, the viruses can combine and mutate into a novel strain of high virulence that can transmit efficiently among humans.

The influenza A virus genome encodes for 11 genes. Four proteins, HA, NS1, PB1-F2, and PB2, are recognized as major determinants for pathogenicity of influenza, with PB1-F2 as the most recently discovered protein. Although the host barrier for avian viruses to spread in humans is multigenic, the receptor binding specificity of $\mathrm{HA}$ is a major obstacle for direct transmission of avian viruses to humans. In general, human influenza viruses tend to bind to $\mathrm{SA} \alpha 2$, $6 \mathrm{Gal}$ receptors, whereas avian viruses favor SA $\alpha 2,3 \mathrm{Gal}$ receptors. Adaptation of avian virus to humans likely requires a shift in receptor binding specificity of the virus from avian-type to human-type. In humans, the SA $\alpha 2$, 6Gal receptor is expressed mainly in the upper airway, but the SA $\alpha 2,3 \mathrm{Gal}$ receptor is expressed in alveoli and the terminal bronchiole [5]. Clinical data illustrated that an influenza virus that could bind to both SA $\alpha 2,3 \mathrm{Gal}$ and SA $\alpha 2,6 \mathrm{Gal}$ receptors is highly pathogenic.

The receptor binding site of HA comprises three sec- 
ondary structure elements: the 190 helix (residues 190 198), the 130 loop (residues 135 - 138) and the 220 loop (residues 221 - 228) that form the sides of the site with the base made up of the conserved residues Tyr 98, Trp 153, His 183 and Tyr 195 (H3 numbering) [6]. The receptor binding affinity of HA could be altered by several key residues, and a wide variety of such mutations have been identified. A single mutation D225G changed the binding of one strain of $1918 \mathrm{H} 1 \mathrm{~N} 1$ from pure humantype binding to human and avian types (dual binding) [7]. Amino acids at positions 226 and 228 (H3 numbering) could affect binding preference of several subtypes including $\mathrm{H} 2, \mathrm{H} 3, \mathrm{H} 4$ and $\mathrm{H} 9$, and on the other hand the changes at positions 190 and 225 could influence H1 subtype. Computing modeling also indicated that HA amino acid residues, Tyr 98, Val 135, Ser 136, Ser 137, Trp 153, Ile 155, His 183, Glu 190, Leu 194, and Gln 226 , are important for the avian-type binding of $\mathrm{H} 5 \mathrm{~N} 1$ HA, with Gln 226 as a very critical residue in this regard. Further, amino acid residues, Leu 133, Val 135, Trp 153, Ile 155, Glu 190, and Lys 193, are important for the human-type binding of H5N1 HA [8]. Interestingly, a bioinformatics approach, termed informational spectrum method (ISM), was applied to the HA1 domain of HA in the study of its receptor binding specificity [9-13].

Besides the role of HA plays in host range restriction, the cooperative contributions to human adaptation from other proteins of avian and swine influenza were also investigated. Support vector machines, entropy, and mutual information were utilized to uncover the unique molecular features of these viruses [14-22]. Most recently, Random Forests [23] were applied successfully to tackle the same problem, where novel host markers in the proteins and genes of pandemic 2009 H1N1 were identified $[24,25]$. These findings highlighted that host adaptation of influenza viruses is a complex and polygenic trait. While there have been extensive studies on host markers in general influenza species including avian and swine viruses, the purpose of this study was to narrow the focus by identifying the distinct characteristics of the highly pathogenic avian $\mathrm{H} 5 \mathrm{~N} 1$ from Asia and the low pathogenic avian H5N1 from North America, in comparison with human and swine H5N1.

\section{MATERTIALS AND METHDOS}

\subsection{Sequence Data}

The sequences of influenza were retrieved from the Influenza Virus Resource of the National Center for Biotechnology Information (NCBI). Only the full length and unique sequences were selected. All sequences used in this study were aligned with MAFFT [26].

\subsection{Informational Spectrum Method}

The informational spectrum method (ISM) is a bioin-
Table 1. Characteristic IS frequencies of HA proteins in 2009 H1N1, swine H1N1/H1N2, avian H1N1, and A/South Carolina/1/18 (H1N1).

\begin{tabular}{|c|c|c|c|c|c|}
\hline Subtype & $\begin{array}{c}2009 \\
\text { H1N1 }\end{array}$ & $\begin{array}{c}\text { Swine } \\
\text { H1N2/H1N1 }\end{array}$ & $\begin{array}{l}\text { Avian } \\
\text { H5N1 }\end{array}$ & $\begin{array}{c}\text { Human } \\
\text { H1N1 }\end{array}$ & $\begin{array}{c}\text { A/South Caro- } \\
\text { lina/1/18 } \\
\text { (H1N1) }\end{array}$ \\
\hline & & $\mathrm{F}(0$. & $\mathrm{F}(0.076)$ & $\mathrm{F}(0.236)$ & $\mathrm{F}(0.258)$ \\
\hline
\end{tabular}

formatics technique that can be used to analyze protein sequences [27]. The idea is to translate the protein sequences into numerical sequences based on electron-ion interaction potential (EIIP) of each amino acid. Then the Discrete Fourier Transform (DFT) can be applied to these numerical sequences, and the resulting DFT coefficients are used to produce the energy density spectrum. The informational spectrum (IS) comprises the frequencies and the amplitudes of this energy density spectrum. According to the ISM theory, the peak frequencies of IS of a protein sequence reflect its biological or biochemical functions. The ISM was successfully applied to quantify the effects of HA mutations on the receptor binding preference in [10] and reveal the change of receptor binding selection caused by the mutations identified in [28] and [12]. Table 1 shows several common IS frequencies identified in $[12,13]$.

It was observed in [11] that some of the influenza strains displayed dual HA receptor binding preference. Consequently, in this study we used top two IS frequencies, one primary and one secondary, to describe the HA receptor selection.

\subsection{Entropy and Mutual Information}

In information theory [29,30], entropy is a measure of the uncertainty associated with a random variable. Let $x$ be a discrete random variable that has a set of possible values $\left\{a_{1}, a_{2}, a_{3}, \ldots, a_{n}\right\}$ with probabilities $\left\{p_{1}, p_{2}, p_{3}, \ldots\right.$, $\left.p_{n}\right\}$ where $P\left(x=a_{i}\right)=p_{i}$. The entropy $\mathrm{H}$ of $x$ is

$$
H(x)=-\sum_{i} p_{i} \log p_{i}
$$

The mutual information of two random variables is a quantity that measures the mutual dependence of the two variables or the average amount of information that $x$ conveys about $y$, which can defined as

$$
I(x, y)=H(x)+H(y)-H(x, y)
$$

where $H(x)$ is the entropy of $x$, and $H(x, y)$ is the joint entropy of $x$ and $y . I(x, y)=0$ if and only if $x$ and $y$ are independent random variables.

In the current study, each of the n columns in a multiple sequence alignment of a set of influenza protein sequences of length $\mathrm{N}$ is considered as a discrete random variable $x_{i}(1 \leq i \leq \mathrm{N})$ that takes on one of the $20(\mathrm{n}=20)$ 
amino acid types with some probability. $H\left(x_{i}\right)$ has its

Table 2. Amino acids near and at the cleavage site in HA consensus sequences of different origins.

\begin{tabular}{ccc}
\hline Virus & Cleavage site & $\begin{array}{c}\text { Number of basic } \\
\text { amino acids }\end{array}$ \\
\hline $\begin{array}{c}\text { Human H1N1 } \\
\text { 2009 H1N1 }\end{array}$ & NIPS - --- IQSRGLF & 1 \\
AVPS ---- IQSRGLF & 1 \\
$\begin{array}{c}\text { (H5N1) } \\
\text { North American avian }\end{array}$ & NTPQRERRRKKRGLF & 7 \\
H5N1 & NPQ---- RETRGLF & 2 \\
2010: Asian avian H5N1 & NSPQREGRRRKRGLF & 6 \\
2009: Asian avian H5N1 & NSPQRERRRRKRGLF & 7 \\
2008: Asian avian H5N1 & NSPQRERRRKKRGLF & 7 \\
2007: Asian avian H5N1 & NSPQRERRRKKRGLF & 7 \\
2006: Asian avian H5N1 & NSPQRERRRKKRGLF & 7 \\
2005: Asian avian H5N1 & NSPQRERRRKKRGLF & 7 \\
2004: Asian avian H5N1 & NSPQRERRRKKRGLF & 7 \\
2010: Human H5N1 & NSPQGERRRKKRGLF & 6 \\
2009: Human H5N1 & NSPQGERRRKKRGLF & 6 \\
2008: Human H5N1 & NSPLRERRRKKRGLF & 7 \\
2007: Human H5N1 & NSPQRERRRKKRGLF & 7 \\
2006: Human H5N1 & NSPQRESRRKKRGLF & 6 \\
2005: Human H5N1 & NSPQRERRRKKRGLF & 7 \\
2004: Human H5N1 & NSPQRERRRKKRGLF & 7 \\
\hline
\end{tabular}

minimum value 0 if all the amino acids at position $i$ are the same, and achieves its maximum if all the 20 amino acid types appear with equal probability at position $i$, which can be verified by the Lagrange multiplier technique. A position of high entropy means that the amino acids are often varied at this position. While $H\left(x_{i}\right)$ measures the genetic diversity at position $i$ in our current study, $I(x, y)$ measures the correlation between amino acid substitutions at positions $i$ and $\mathrm{j}$.

\section{RESULTS}

\subsection{Cleavage Site in HA}

Avian H5N1 can be divided into two groups, highly and low pathogenic viruses based on their difference in virulence. The HA protein playing a key role in pathogenicity has two domains, HA1 and HA2, which are cleaved from their precursor HA0 by cellular proteases. Normally, mammalian and low pathogenic avian viruses carry an HA cleavage site with a monobasic motif, whereas high pathogenic avian viruses possess a K/R polybasic HA cleavage site, which is hydrolyzed by a broad range of proteases in the host cells. Therefore, the polybasic HA cleavage site is a salient virulence feature. Removal of the polybasic HA cleavage site results in a drastic decrease in pathogenicity. However, introduction of a polybasic motif into the HA cleavage site of a low pathogenic avian strain might or might not transform it into a highly pathogenic strain, indicating the existence of additional virulence determinants in HA or other proteins [31]. It turned out the amino acids V346 and S346
(323 in $\mathrm{H} 3$ numbering) adjacent to the cleavage site played a central role in virulence as well [32] (Table 2), which demonstrated experimentally that the presence of V346 reduced the virulence whereas S346 produced the opposite results. Clearly, North America avian H5N1 had V346 and its Asian counterpart had S346 (Table 2), in addition to the difference in their cleavage site.

\subsection{Receptor Binding Specificity}

\subsubsection{Mutations in HA Capable of Changing Binding Preference}

It is well established that avian viruses will have to acquire human-type receptor preference for sustained replication and transmission in humans. The receptor binding affinity is primarily determined by the amino acids at the receptor binding domain (RBD) along with other critical sites [9-11]. According to [33], the amino acids at the sites implicated in receptor specificity were listed in Table 3 (H3 numbering), which showed that the amino acid differences between avian, human, and swine H5N1 only occurred at sites 193 and 216, and their key sites $190 \mathrm{E}$ and $225 \mathrm{G}$ retained the avian-type binding preference. This finding supported that viruses with avian specific receptor binding properties could replicate and cause infection in humans and swine, but could not do so efficiently. To offer a comparison with human viruses, the related amino acids in the human H1N1 HA consensus sequence from 1918 to 2008 was added to the table. H5 HA mutation K193R increased the human-type binding, however the virus with mutation R216K or S227N did not bind to human-type receptor [34]. The frequent occurrences of mutations K193R and R216K observed in Table 3 implied the inclination of H5N1 to increase its human-type binding, which could be a concern. North American avian H5N1 had E216 and P221, but Asian avian, human, and swine H5N1 all had K(R) 221 and S221. Considering the corresponding amino acids at the same sites in human H1N1 HA, the two amino acids E216 and P221 in North American avian H5N1 appeared to favor human-type binding.

In addition to the critical mutations discussed above, avian H5N1 HA mutations L133V, A137V [35], N186K, Q196R [36], E190D, G225D [37], G228S [38] were shown to enhance its human-type binding, and mutations Q226L and G228S to reduce its avian-type binding affinity [35], and mutation S227N to reduce its avian-type binding and increase its human-type binding affinity [39].

Even though pandemic 2009 H1N1 was known for its efficient transmission among humans, its HA was of classical swine lineage [40]. Its HA carried D190, E216, P221, D225, and E227 (Table 3), the first two were a feature for avian-type binding whereas the second two 
were for human-type binding. A new mutation E391K in at a known antigenic site and could influence the HA HA of 2009 H1N1 was found recently [41], which was

Table 3. Amino acids at critical sites (H3 numbering) for receptor selection in the HA consensus sequences of various origins. The distances in the table represent the Hamming distances between human H1N1 and others based on the amino acids at the 17 sites in the table.

\begin{tabular}{|c|c|c|c|c|c|c|c|c|c|c|c|c|c|c|c|c|c|c|}
\hline Position & 98 & 136 & 153 & 183 & 186 & 190 & 193 & 194 & 195 & 196 & 216 & 221 & 222 & 225 & 226 & 227 & 228 & Dist \\
\hline human H1N1 & $\mathrm{Y}$ & $\mathrm{S}$ & $\mathrm{W}$ & $\mathrm{H}$ & $\mathrm{P}$ & $\mathrm{D}$ & $\mathrm{A}$ & $\mathrm{L}$ & $\mathrm{Y}$ & $\mathrm{H}$ & $E$ & $\mathrm{P}$ & $\mathrm{K}$ & $\mathrm{D}$ & Q & $\mathrm{E}$ & G & 0 \\
\hline $2009 \mathrm{H} 1 \mathrm{~N} 1$ & $\mathrm{Y}$ & $\mathrm{T}$ & W & $\mathrm{H}$ & $\mathrm{S}$ & D & $\mathrm{S}$ & $\mathrm{L}$ & $\mathrm{Y}$ & Q & $\mathrm{E}$ & $\mathrm{P}$ & $\mathrm{K}$ & $\mathrm{D}$ & $\mathrm{Q}$ & $\mathrm{E}$ & $\mathrm{G}$ & 4 \\
\hline Swine H5N1 & $\mathrm{Y}$ & $\mathrm{S}$ & W & $\mathrm{H}$ & $\mathrm{N}$ & E & $\mathrm{K}$ & $\mathrm{L}$ & $\mathrm{Y}$ & Q & K & $\mathrm{S}$ & $\mathrm{K}$ & $\mathrm{G}$ & $\mathrm{Q}$ & $\mathrm{S}$ & $\mathrm{G}$ & 8 \\
\hline 2010:Asia avian H5N1 & $\mathrm{Y}$ & $\mathrm{S}$ & W & $\mathrm{H}$ & $\mathrm{N}$ & $\mathrm{E}$ & $\mathrm{R}$ & $\mathrm{L}$ & $\mathrm{Y}$ & Q & $\mathrm{K}$ & $\mathrm{S}$ & K & G & Q & $\mathrm{S}$ & G & 8 \\
\hline 2009:Asian avian H5N1 & $\mathrm{Y}$ & $\mathrm{S}$ & W & $\mathrm{H}$ & $\mathrm{N}$ & $\mathrm{E}$ & $\mathrm{R}$ & $\mathrm{L}$ & $\mathrm{Y}$ & $\mathrm{Q}$ & $\mathrm{K}$ & $\mathrm{S}$ & $\mathrm{K}$ & G & $\mathrm{Q}$ & $\mathrm{S}$ & G & 8 \\
\hline 2008:Asian avian H5N1 & $\mathrm{Y}$ & $\mathrm{S}$ & W & $\mathrm{H}$ & $\mathrm{N}$ & $\mathrm{E}$ & $\mathrm{R}$ & $\mathrm{L}$ & $\mathrm{Y}$ & $\mathrm{Q}$ & $\mathrm{K}$ & $\mathrm{S}$ & $\mathrm{K}$ & G & $\mathrm{Q}$ & $\mathrm{S}$ & G & 8 \\
\hline 2007:Asian avian H5N1 & $\mathrm{Y}$ & $\mathrm{S}$ & W & $\mathrm{H}$ & $\mathrm{N}$ & $\mathrm{E}$ & $\mathrm{K}$ & $\mathrm{L}$ & $\mathrm{Y}$ & $\mathrm{Q}$ & $\mathrm{K}$ & $\mathrm{S}$ & $\mathrm{K}$ & G & $\mathrm{Q}$ & $\mathrm{S}$ & G & 8 \\
\hline 2006:Asian avian H5N1 & $\mathrm{Y}$ & $\mathrm{S}$ & W & $\mathrm{H}$ & $\mathrm{N}$ & $\mathrm{E}$ & $\mathrm{K}$ & $\mathrm{L}$ & $\mathrm{Y}$ & $\mathrm{Q}$ & $\mathrm{K}$ & $\mathrm{S}$ & K & G & $\mathrm{Q}$ & $\mathrm{S}$ & G & 8 \\
\hline 2005:Asian avian H5N1 & $\mathrm{Y}$ & $\mathrm{S}$ & W & $\mathrm{H}$ & $\mathrm{N}$ & $\mathrm{E}$ & $\mathrm{K}$ & $\mathrm{L}$ & $\mathrm{Y}$ & $\mathrm{Q}$ & $\mathrm{K}$ & $\mathrm{S}$ & $\mathrm{K}$ & G & Q & $\mathrm{S}$ & G & 8 \\
\hline 2004:Asian avian H5N1 & $\mathrm{Y}$ & $\mathrm{S}$ & W & $\mathrm{H}$ & $\mathrm{N}$ & $\mathrm{E}$ & K & $\mathrm{L}$ & $\mathrm{Y}$ & $\mathrm{Q}$ & $\mathrm{R}$ & $\mathrm{S}$ & $\mathrm{K}$ & $\mathrm{G}$ & $\mathrm{Q}$ & $\mathrm{S}$ & G & 8 \\
\hline 2010:human H5N1 & $\mathrm{Y}$ & $\mathrm{S}$ & W & $\mathrm{H}$ & $\mathrm{N}$ & $\mathrm{E}$ & $\mathrm{R}$ & $\mathrm{L}$ & $\mathrm{Y}$ & $\mathrm{Q}$ & $\mathrm{K}$ & $\mathrm{S}$ & $\mathrm{K}$ & G & Q & $\mathrm{S}$ & G & 8 \\
\hline 2009:human H5N1 & $\mathrm{Y}$ & $\mathrm{S}$ & $\mathrm{W}$ & $\mathrm{H}$ & $\mathrm{N}$ & $\mathrm{E}$ & $\mathrm{R}$ & $\mathrm{L}$ & $\mathrm{Y}$ & Q & $\mathrm{K}$ & $\mathrm{S}$ & $\mathrm{K}$ & $\mathrm{G}$ & $\mathrm{Q}$ & $\mathrm{S}$ & G & 8 \\
\hline 2008:human H5N1 & $\mathrm{Y}$ & $\mathrm{S}$ & $\mathrm{W}$ & $\mathrm{H}$ & $\mathrm{N}$ & $\mathrm{E}$ & $\mathrm{K}$ & $\mathrm{L}$ & $\mathrm{Y}$ & Q & $\mathrm{K}$ & $\mathrm{S}$ & $\mathrm{K}$ & $\mathrm{G}$ & $\mathrm{Q}$ & $\mathrm{S}$ & G & 8 \\
\hline 2007:human H5N1 & $\mathrm{Y}$ & $\mathrm{S}$ & W & $\mathrm{H}$ & $\mathrm{N}$ & $\mathrm{E}$ & $\mathrm{R}$ & $\mathrm{L}$ & $\mathrm{Y}$ & Q & $\mathrm{K}$ & $\mathrm{S}$ & $\mathrm{K}$ & G & Q & $\mathrm{S}$ & G & 8 \\
\hline 2005:human H5N1 & $\mathrm{Y}$ & $\mathrm{S}$ & $\mathrm{W}$ & $\mathrm{H}$ & $\mathrm{N}$ & $\mathrm{E}$ & $\mathrm{K}$ & $\mathrm{L}$ & $\mathrm{Y}$ & Q & K & $\mathrm{S}$ & $\mathrm{K}$ & $\mathrm{G}$ & Q & $\mathrm{S}$ & G & 8 \\
\hline 2004:human H5N1 & $\mathrm{Y}$ & $\mathrm{S}$ & $\mathrm{W}$ & $\mathrm{H}$ & $\mathrm{N}$ & $\mathrm{E}$ & $\mathrm{K}$ & $\mathrm{L}$ & $\mathrm{Y}$ & Q & $\mathrm{R}$ & $\mathrm{S}$ & K & $\mathrm{G}$ & $\mathrm{Q}$ & $\mathrm{S}$ & $\mathrm{G}$ & 8 \\
\hline
\end{tabular}
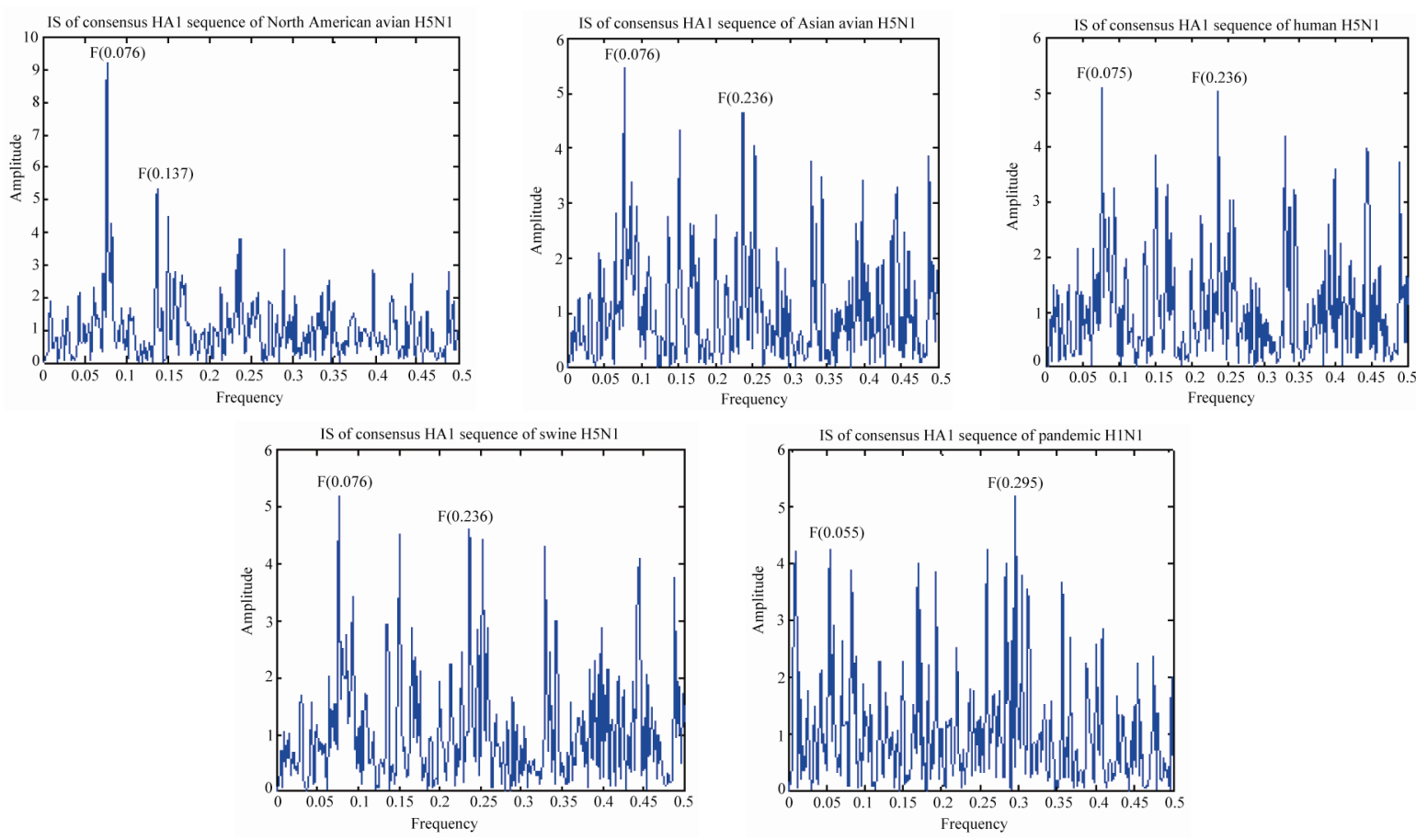

Figure 1. IS of consensus H5N1 HA1 of different origins.

membrane fusion. It is expected this novel virus will continue to mutate $[28,41,42]$.

\subsubsection{Receptor Binding Preferences}

Some influenza viruses tend to display dual binding preference at two different frequencies, one as their primary frequency and one as secondary [11]. With the ISM, Asia avian, human, and swine H5N1 had $\mathrm{F}(0.0765)$ (avian- type binding) as their primary binding frequency and $\mathrm{F}(0.236)$ (seasonal human H1N1 binding) as secondary (Figure 1). Our bioinformatics discovery was in agreement with the experimental results in [43], which showed that avian H5N1 had strong avian-type binding and weak human-type binding. Distinctly, North American avian H5N1 had $F(0.0765)$ and $F(0.137)$ as its primary and secondary frequencies respectively. The HA protein of 
North America avian H5N1 didn't carry the highly pathogennic avian signature amino acids RERR at the its cleavage site. Adding these four amino acids to the cleavage site of North America avian viruses didn't change

Table 4. Hamming distances between the concatenated protein sequences of $\mathrm{H} 5 \mathrm{~N} 1$ of different origins. Due to limited number of sequences for Swine ("S") and North American H5N1 ("N"), we formed one consensus from different years. Asian H5N1 ("A") had seven consensuses by year (2004-2010), while human H5N1 ("H") had five consensuses by year (2004-2008).

\begin{tabular}{cccccc}
\hline YearlDist & $(\mathrm{N}, \mathrm{A})$ & $(\mathrm{S}, \mathrm{A})$ & $(\mathrm{N}, \mathrm{H})$ & $(\mathrm{S}, \mathrm{H})$ & $(\mathrm{A}, \mathrm{H})$ \\
\hline 2010 & 240 & 112 & & & \\
2009 & 197 & 110 & & & \\
2008 & 186 & 44 & 200 & 65 & 40 \\
2007 & 186 & 28 & 206 & 56 & 50 \\
2006 & 163 & 61 & 214 & 35 & 88 \\
2005 & 162 & 48 & 196 & 32 & 51 \\
2004 & 171 & 68 & 195 & 47 & 28 \\
\hline
\end{tabular}

their primary and secondary frequencies, implying that these amino acids were not relevant for HA binding. As a comparison, the primary $\mathrm{F}(0.295)$ (human-type) and the secondary $\mathrm{F}(0.055)$ (swine-type) frequencies of 2009 H1N1 were included in Figure 1.

This kind of subtle difference in receptor binding preference as reflected in the secondary frequency was also observed in the two clusters of $2009 \mathrm{H} 1 \mathrm{~N} 1$ found in [44], where both of them shared the same primary binding frequency while differed in their secondary frequency. One had swine secondary frequency and the other had 1918 Spanish flu frequency [45]. As a whole group, the 2009 H1N1 HA sequences showed its swine-type receptor selection in the early months of its run in 2009, but this selection gradually disappeared in the late months [28]. As an extension of the work in [28], a recent report using affinity propagation identified six clusters of 2009 H1N1 HA sequences collected from May 2010 to February 2011 and found the HA receptor preference of each cluster [46].

\subsection{Hamming Distances between H5N1 Sequences of Different Origins}

One easy way to compare two sequences is to calculate their Hamming distance. To present a holistic view for the similarities of influenza sequences under the current study, we concatenated the consensus sequences of different proteins from each species including HA, NA, M1, M2, NS1, NS2, NP, PA, PB1, PB1-F2, and PB2. Because there were many Asian avian $\mathrm{H} 5 \mathrm{~N} 1$ sequences available, the consensus was formed by year. Table 4 presents Hamming distances of consensus sequences of different origins. When no sequences were available in a particular year, we left the table entry empty in that year.

The distances between Asian avian, human, and swine
H5N1 were close to each other. However, there was a clear increase in the distances of swine and Asian avian H5N1 in 2009 and 2010. Unfortunately, there were no data for distances of swine and human as well as swine and Asian avian H5N1 in 2009 and 2010. Finally, the distances from North American avian H5N1 to other species were the largest in Table 4. In summary, human and swine H5N1 sequences were closer to Asian avian H5N1 than to North American avian H5N1.

\subsection{Characteristic Sites between Asian and North American Avian H5N1}

Here we first summarized some amino acid differences in HA, NA, NS1, and PB2 between Asian and North American avian $\mathrm{H} 5 \mathrm{~N} 1$ because of their crucial functions in the pathogenicity of influenza. As discussed in section 3.1, Asian avian H5N1 HA possessed a series of basic amino acids (RRKKR) at the cleavage site, a determinant of high pathogenicity for avian virus and a marker its North American counterpart lacked. In addition, all five consensuses of human H5N1 NS1 (2004-2008) carried a deletion of 5 amino acids at positions $80-84$ and all swine H5N1 strains but one had this deletion, while Asian avian H5H1 contained this deletion in 2007, 2008, and 2010. In contrast, North American avian H5H1 had full length NS1. This deletion in NS1 seems to increase pathogenicity in chickens and mice [47]. Large-scale sequence analysis of avian viruses identified a PDZ ligand domain of the X-S/T-X-V type at the C-terminus of NS1. Typically, highly pathogenic H5N1 NS1 has ESEV or EPEV while most low pathogenic human viruses contain a different motif RSKV or RSEV, which cannot bind PDZ-containing proteins. Most of the Asian and North American avian, human, and swine H5N1 strains in our dataset had an avian-type motif ESEV

All North American avian and swine H5N1 strains had E at PB2 627, but both human and Asian avian $\mathrm{H} 5 \mathrm{~N} 1 \mathrm{had}$ a mixture of $\mathrm{E}$ and $\mathrm{K}$ at 627 . In general, $627 \mathrm{~K}$ is a marker for human influenza and $627 \mathrm{E}$ is for avian viruses. PB2-627K confers to avian H5N1 the advantage of efficient growth in the upper and lower respiratory tracts of mammals [48].

Many Asian avian, human, and swine H5N1 strains carried a deletion of 20 amino acids in the NA stalk (residues 49 - 68), which is also a indicator for high virulence. But only two of the North American avian strains contained a deletion of 21 amino acids in the NA stalk (residues 54 - 74). The active site of NA is lined by several conserved residues $(117$ - 119, 133 - 138, 146 - 152, 156, 179, 180, 196 - 200, 223 - 228, 243 - 247, 277, 278, 293, 295, $344-347,368,401,402$, and $426-441)$ that participate in recognition of its substrate [40]. In [49] the role of second active site in NA was assessed. It found 
that in avian NA the interaction between this second site and the primary site is essential for NA function, and the NA of 2009 H1N1 has retained some of the important
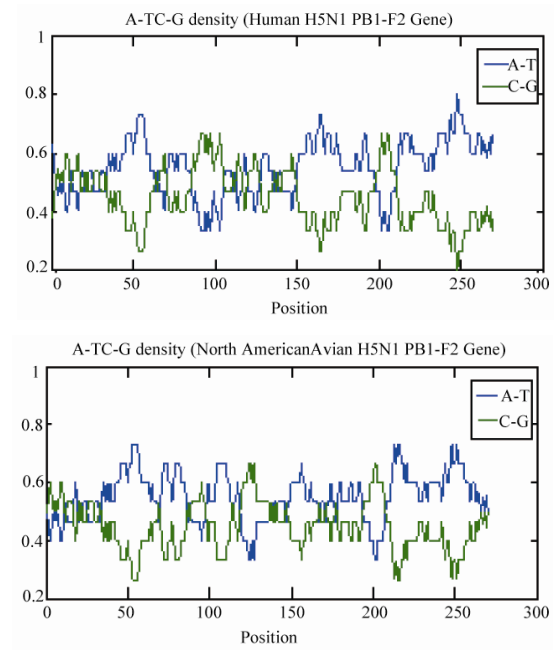

features of the second site. Following [49], we listed the amino acids at the positions that are lined with the sec-
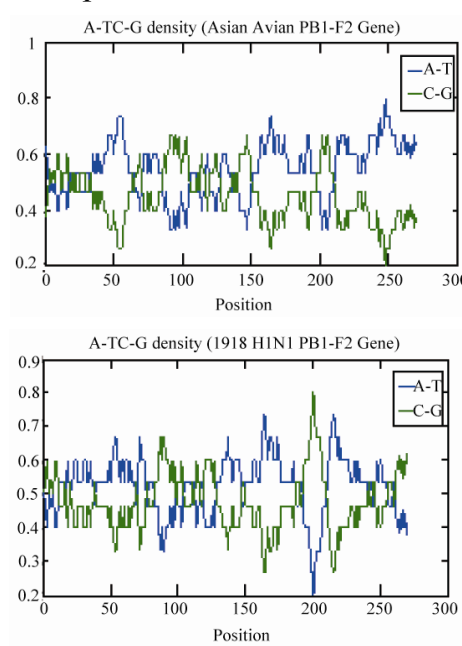
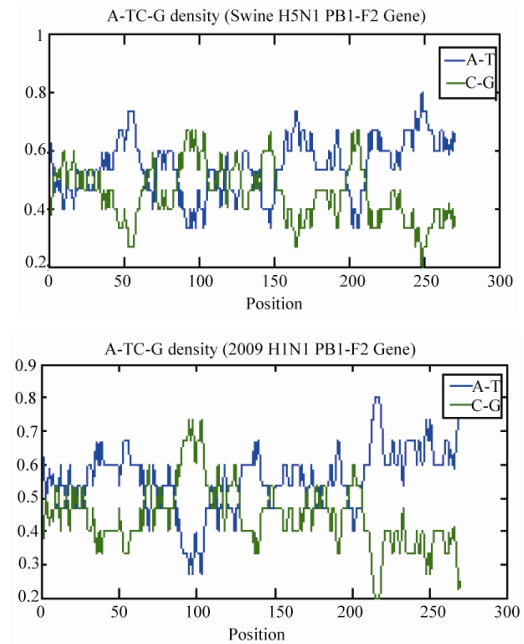

Figure 2. AT/CG density curves of PB1-F2 of different origins with sliding window size = sequence length/20.
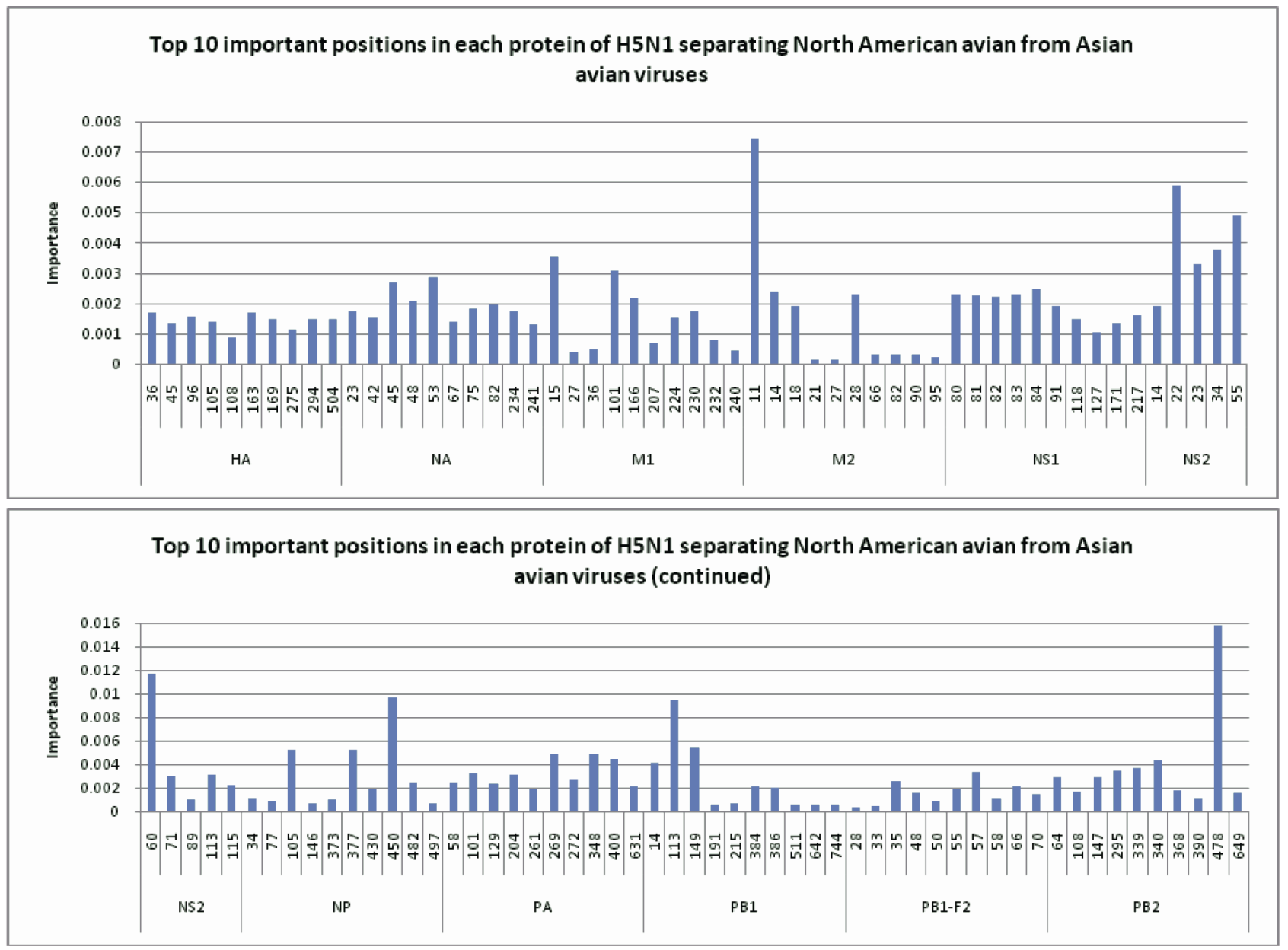

Figure 3. Top 10 important positions in each protein of H5N1 that could distinguish North American and Asian avian H5N1. 
doi:10.4236/ajmb.2011.12007 Published Online July 2011 (http://www.SciRP.org/journal/ajmb/).

ond site (N2 numbering) (Table 5). It appeared that the main amino acid difference occurred at position 369 for H5N1 and A/California/04/2009(H1N1) (Cal_04_09).

The GC content of PB1-F2 of 2009 H1N1 is more similar to swine influenza than to humans [50], although its $\mathrm{PB} 1$ gene segment was derived from human H3N2

Table 5. Amino acid comparison at second active site residues in NA of H5N1 and Cal_04_09. The conserved residues are highlighted (N2 numbering).

\begin{tabular}{cccc}
\hline & $366-373$ & $399-403$ & $430-433$ \\
\hline Asia & KSTNSRSG & AITDWS & RPKE \\
North America & KSTSSRSG & AITDWS & RPKE \\
Human & KSTNSRSG & AITDWS & RPKE \\
Swine & KSTNSRSG & AITDWS & RPKE \\
Cal_04_09 & KSISSRNG & GINEWS & RPKE \\
\hline
\end{tabular}

Table 6. Consensus amino acids at top 10 important positions in each protein of $\mathrm{H} 5 \mathrm{~N} 1$ distinguishing Asian and North American avian viruses. There were several positions that had two frequent amino acids. A “-” stands for a deletion.

\begin{tabular}{|c|c|c|c|c|c|c|c|c|c|}
\hline Pos & 36 & 45 & 96 & 105 & 108 & 163 & 169 & 2 & 945 \\
\hline North Ame & $\mathrm{F}$ & $\mathrm{K}$ & S & M & $\mathrm{T}$ & T & $\mathrm{V}$ & $\mathrm{D}$ & $\overline{\mathrm{D}}$ \\
\hline Asia & $\mathrm{T}$ & $\mathrm{N}, \mathrm{D}$ & $\mathrm{N}$ & $\mathrm{L}$ & 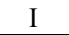 & G, S & Q & $\mathrm{N}$ & \\
\hline Posit & 23 & 42 & 45 & 48 & 53 & 67 & 75 & 82 & 234241 \\
\hline North & $\mathrm{V}$ & $\mathrm{S}$ & $\mathrm{Y}$ & T & V & I & I & $P$ & I \\
\hline & I, M & $\mathrm{N}$ & Q & $\mathrm{P}$ &,- I & - & $\mathrm{L}$ & $\mathrm{S}$ & $\mathrm{V}$ \\
\hline Posi & 15 & 27 & 36 & 101 & 166 & 207 & 224 & 230 & 232240 \\
\hline orth & $\mathrm{V}$ & $\mathrm{R}$ & $\mathrm{N}$ & $\mathrm{R}$ & V & $\mathrm{S}$ & $\mathrm{S}$ & K & D \\
\hline & $\mathrm{I}$ & K & $\mathrm{N}$ & K & A & $\mathrm{N}$ & $\mathrm{N}$ & $\mathrm{R}$ & $\mathrm{N}$ \\
\hline Posi & 11 & 14 & 18 & 21 & 27 & 28 & 66 & 82 & $90 \quad 95$ \\
\hline North & $\mathrm{T}$ & G & $\mathrm{R}$ & $\mathrm{D}$ & V & I & $\mathrm{E}$ & S & $\mathrm{H}$ \\
\hline & 1 & E & $\mathrm{R}$ & D & V & V & E,A & $\mathrm{S}$ & $\mathrm{H}$ \\
\hline Posi & 80 & 81 & 82 & 83 & 84 & 91 & 118 & 127 & 171217 \\
\hline Vorth & $\mathrm{T}$ & I & A & S & V & $\mathrm{T}$ & $\mathrm{R}$ & $\mathrm{N}$ & D \\
\hline & , A, T &,- I &,$- \mathrm{A}$ &,$- \mathrm{S}$ & $-, \mathrm{S}, \mathrm{V}$ & $\mathrm{T}$ & K & $\mathrm{T}$ & $\mathrm{N}$ \\
\hline Pos & 14 & 22 & 23 & 34 & 55 & 60 & 71 & 89 & 113115 \\
\hline Nort & $\mathrm{M}$ & G & $\mathrm{S}$ & $\bar{Q}$ & $\mathrm{~L}$ & S & $\mathrm{Q}$ & I & I \\
\hline & $\mathrm{V}$ & A & $\mathrm{S}$ & Q & $\mathrm{F}$ & I & $\mathrm{Q}$ & I & A \\
\hline Posi & 34 & 77 & 105 & 146 & 373 & 377 & 430 & 450 & 482497 \\
\hline North & G & K & M & A & $\mathrm{T}$ & $\mathrm{S}$ & $\mathrm{T}$ & $\mathrm{N}$ & $\mathrm{D}$ \\
\hline & G & $\mathrm{R}$ & V & A & A & $\mathrm{N}$ & $\mathrm{T}$ & $\mathrm{N}$ & $\mathrm{N}$ \\
\hline Pos & 58 & 101 & 129 & 204 & 261 & 269 & 272 & 348 & 400631 \\
\hline North & G & $\mathrm{E}$ & I & $\mathrm{R}$ & $\mathrm{L}$ & K & $\mathrm{D}$ & $\mathrm{L}$ & \\
\hline & $\mathrm{G}, \mathrm{S}$ & $\mathrm{D}, \mathrm{E}$ & $\mathrm{I}, \mathrm{T}$ & $\mathrm{R}, \mathrm{K}$ & $\mathrm{L}, \mathrm{M}$ & $\mathrm{R}$ & $\mathrm{D}$ & I & $\mathrm{S}, \mathrm{PG}, \mathrm{S}$ \\
\hline Posi & 14 & 113 & 149 & 191 & 215 & 384 & 386 & 511 & 642744 \\
\hline North & A & $\mathrm{V}$ & $\mathrm{V}$ & $\mathrm{V}$ & $\mathrm{R}$ & $\mathrm{S}$ & $\mathrm{R}$ & $\mathrm{S}$ & $\mathrm{N}$ \\
\hline & $v$ & I & I & $\mathrm{V}$ & $\mathrm{R}$ & $\mathrm{L}$ & $\mathrm{K}$ & $\mathrm{S}$ & $\mathrm{N}$ \\
\hline Position/PB1-F2 & 28 & 33 & 35 & 48 & 50 & 55 & 57 & 58 & $66 \quad 70$ \\
\hline North & $\mathrm{L}$ & $\mathrm{H}$ & $\mathrm{L}$ & $\mathrm{Q}$ & $\mathrm{D}$ & $\mathrm{T}$ & $\mathrm{S}$ & $\mathrm{L}$ & $\mathrm{E}$ \\
\hline & Q & $\mathrm{P}$ & $\mathrm{S}$ & $\mathrm{P}$ & G & I & Y & W & G \\
\hline Positi & 64 & 108 & 147 & 295 & 339 & 340 & 368 & 390 & 478649 \\
\hline rith & $\mathrm{M}$ & $\mathrm{T}$ & 1 & $v$ & $\mathrm{~K}$ & $\mathrm{R}$ & $\mathrm{R}$ & D & $\overline{\mathrm{V}}$ \\
\hline & I & $\mathrm{T}, \mathrm{A}$ & $\mathrm{T}, \mathrm{I}$ & $\mathrm{V}$ & $\mathrm{T}, \mathrm{K}$ & K & $\mathrm{Q}$, & $\mathrm{N}, \mathrm{I}$ & $\mathrm{V}$ \\
\hline
\end{tabular}

[40]. This discovery prompted us to look at the GC content of PB1-F2 of the viruses under the current study. It turned out the three PB1-F2s of Asian avian, human, and swine $\mathrm{H} 5 \mathrm{~N} 1$ were similar to each other in their GC content, but none of them was close to the GC content of general avian, human, or swine viruses determined in [50] (Figure 2). However, the GC content of PB1-F2 of North American avian H5N1 was similar to the general avian pattern found in [50]. The high pathogenicity of 1918 H1N1 reminded us to analyze the GC content of its PB1-F2 (A/Brevig Mission/1/1918), which turned out to be different from all the other viruses in Figure 2.

Finally, Random Forests [23] were applied to identify

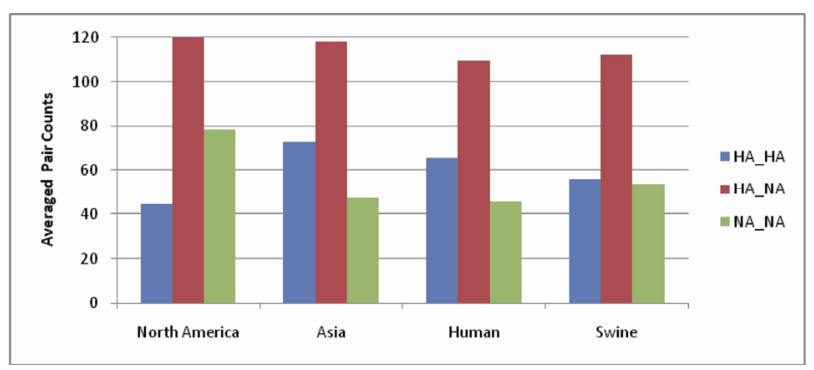

Figure 4. Correlated pair counts within and between H5N1 HA and NA of different origins.

top 10 positions in each protein that could differentiate Asian and North American avian H5N1 with high confidence (Figure 3). The two surface proteins HA and NA had their top 10 positions with similar importance, while the internal proteins had their importance more varied and some of these positions displayed very high importance values. To further elucidate the difference observed in Figure 3, we presented the consensus amino acids at the top 10 positions in Table 6, which could complement the information for the amino acids at the HA binding site in section 3.2. The difference in amino acids at these positions and those in Table 3 contributed to the different HA receptor selections revealed in Figure 1.

\subsection{Correlations within and between $H A$ and NA, and NP, PA, PB1, and PB2 Respectively}

A right balance between the HA receptor binding and the release of progeny virions by NA requires the close cooperation of these two surface proteins. To reveal the correlation patterns for the two proteins of $\mathrm{H} 5 \mathrm{~N} 1$, their mutual information was calculated. We only recorded the positions in these proteins that had a positive MI value. The correlated position pairs of a positive MI value were counted according to their locations in the proteins, and then averaged by the number of sequences in each species. It was evident that the correlation between HA and NA was higher than within across different species. The overall interaction patterns for HA and 
NA of Asian avian and human H5N1 were alike, whereas the North American avian and swine H5N1 displayed distinct patterns (Figure 4).

The interactions among NP and the three proteins PA, $\mathrm{PB} 1$, and $\mathrm{PB} 2$ of the viral polymerase are essential for virus replication and host adaptation. The mutual information was also computed for these four proteins of $\mathrm{H} 5 \mathrm{~N} 1$. As in the HA and NA situation, in general inter-
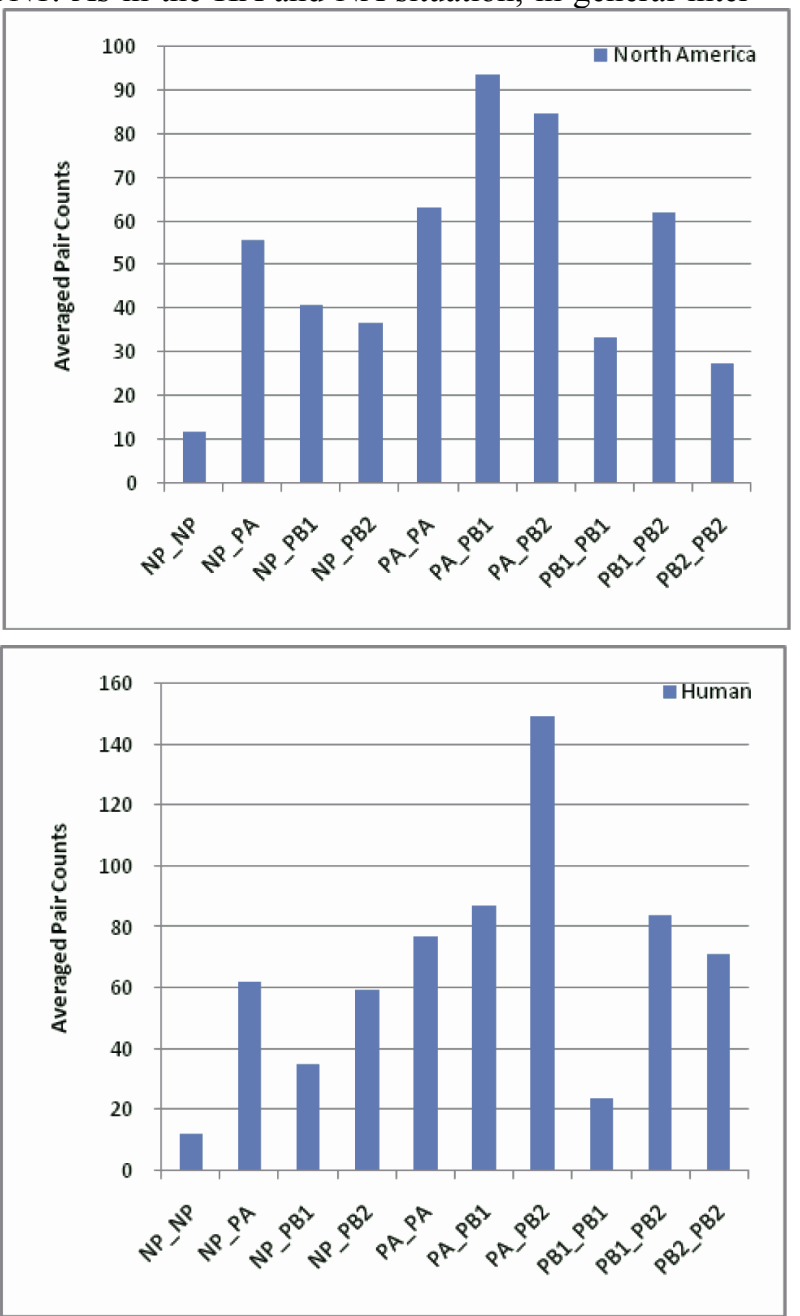

Figure 5. Correlated pair counts within and between H5N1 NP, PA, PB1, and PB2 of different origins.

interesting to note that the most similar two sequences does not always exhibit the most similar correlation patterns [51].

\section{CONCLUSIONS}

It is of prime importance to learn the molecular distinctions between the highly and low pathogenic avian $\mathrm{H} 5 \mathrm{~N} 1$ viruses as we develop the knowledge for avian influenza. This study took Asian and North American avian H5N1 as examples of highly and low pathogenic avian viruses respectively. We sought to investigate several crucial aspects of these viruses including HA protein correlations of the four proteins were stronger than intra-protein across different species (Figure 5). Although the sequences identities of Asian avian, human, and swine $\mathrm{H} 5 \mathrm{~N} 1$ were close to each other (Table 4), only the NP, PA, PB1, and PB2 of Asian avian and swine were similar in their interaction patterns (Figure 5). It is
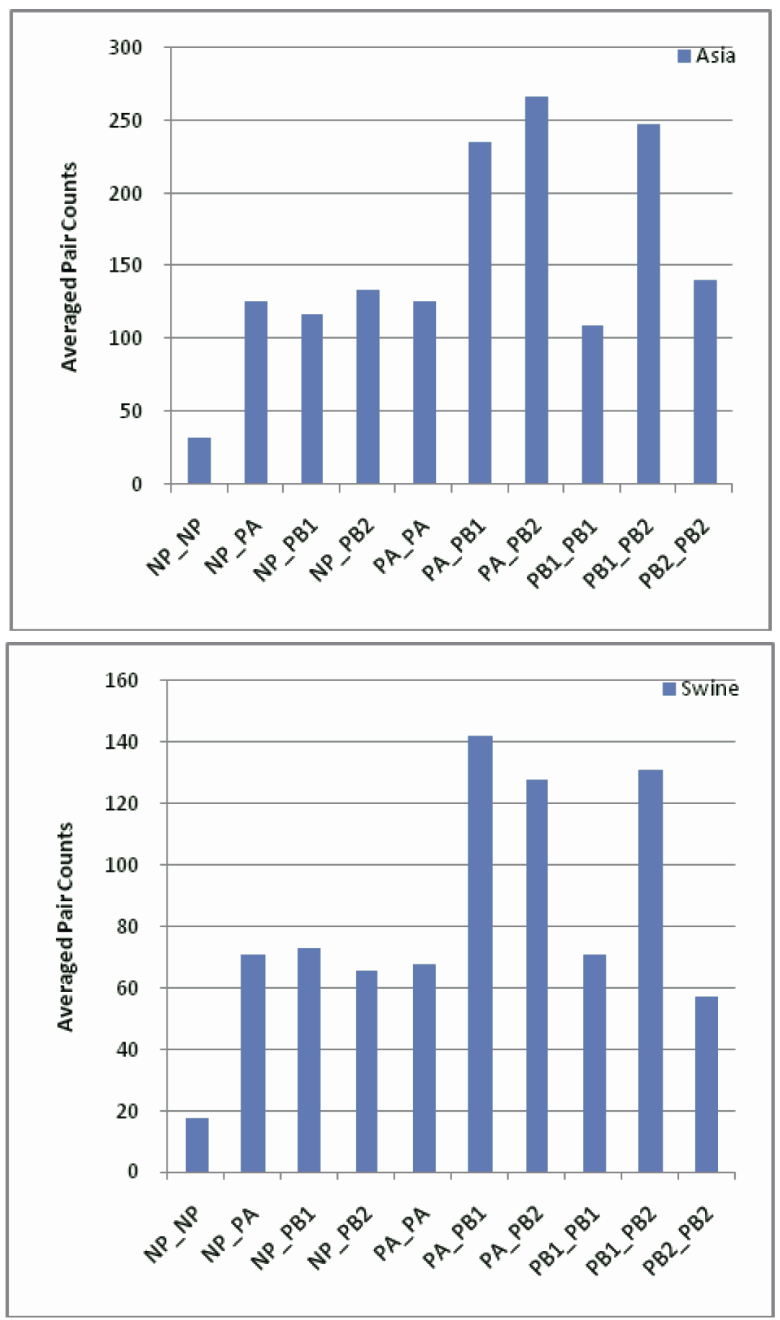

receptor preference and cleavage site, NA second active site, interaction patterns of HA and NA, and NP, $\mathrm{PA}, \mathrm{PB} 1$, and $\mathrm{PB} 2$, and important sites in the proteins of these viruses.

It is believed that a switch from SA $\alpha 2,3 \mathrm{Gal}$ to SA $\alpha 2,3 \mathrm{Gal}$ receptor specificity is a critical step in the adaptation of avian viruses to a human host. The SA $\alpha 2$, 3 Gal specificity of avian influenza viruses makes it difficult for these viruses to be easily transmitted from human to human after avian to human infection. The bioinformatics technique ISM provided an efficient way of revealing the HA receptor selections of avian 
H5N1. The IS analysis on the consensus HA1 sequences of Asian avian, human, and swine H5N1 demonstrated two dominant frequencies: $\mathrm{F}(0.076)$ as primary frequency and $\mathrm{F}(0.236)$ as secondary, while North American avian H5N1 had F(0.076) and F(0.137). Sequence examination also showed that amino acid difference at two critical sites (H3 numbering) for receptor selection were $193 \mathrm{~K}$ and $216 \mathrm{E}$ for North American avian H5N1 and 193R and 216K for Asian avian H5N1 in recent years. The frequent occurrences of mutations K193R and R216K observed in Asian avian H5N1 highlighted the selection pressure on this virus to increase its human-type binding. The different amino acids at sites 193 and 216 plus the top 10 important HA sites identified by Random Forests accounted for the difference in HA receptor specificity of Asian and North American avian H5N1 revealed in this study.

\section{ACKNOWLEDGEMENTS}

We thank Houghton College for its financial support.

\section{REFERENCES}

[1] Xu, X., Subbarao, K., Cox, N.J. and Guo, Y. (1999) Genetic characterization of the pathogenic influenza A/ Goose/Guangdong/1/96 (H5N1) virus: similarity of its hemagg-lutinin gene to those of $\mathrm{H} 5 \mathrm{~N} 1$ viruses from the 1997 outbreaks in Hong Kong. Virology, 261, 15-19. doi:10.1006/viro.1999.9820

[2] Claas, E.C.J., Osterhaus, A.D.M.E., van Beek, R., de Jong, J.C., Rimmelzwaan, G.F., et al. (1998) Human influenza a $\mathrm{H} 5 \mathrm{~N} 1$ virus related to a highly pathogenic avian influenza virus. The Lancet, 351, 472-477. doi:10.1016/S0140-6736(97)11212-0

[3] www.usda.gov/documents/wildbirdstrategicplanpdf.pdf

[4] Bi, Y., Fu, G., Chen, J., Peng, J., Sun, Y., Wang, J., et al. (2010) Novel swine influenza virus reassortants in pigs, China. Emerging Infectious Diseases. http://www.cdc. gov/EID/content/16/7/1162.htm

[5] Shinya, K., Ebina, M., Yamada, S., Ono, M., Kasai, N. and Kawaoka, Y. (2006) Avian flu: Influenza virus receptors in the human airway. Nature, 440, 435-436. doi: $10.1038 / 440435 \mathrm{a}$

[6] Skehel, J.J. and Wiley, D.C. (2000) Receptor binding and membrane fusion in virus entry: The influenza hemagglutinin. Annual Review of Biochemistry, 69, 531-569. doi:10.1146/annurev.biochem.69.1.531

[7] Glaser, L., Stevens, J., Zamarin, D., Wilson, I.A., GarcíaSastre, A., Tumpey, T.M., Basler, C.F., Taubenberger, J.K. and Palese, P. (2005) A single amino acid substitution in 1918 influenza virus hemagglutinin changes receptor binding specificity. Journal of Virology, 79, 11533-11536. doi:10.1128/JVI.79.17.11533-11536.2005

[8] Li, M. and Wang, B. (2006) Computational studies of H5N1 hemagglutinin binding with SA-alpha-2,3-Gal and SA-alpha-2,6-Gal. Biochemical and Biophysical Research Communications, 347, 662-668. doi:10.1016/j.bbrc.2006.06.179

[9] $\mathrm{Hu}, \mathrm{W}$. (2010) Identification of highly conserved domains in gemagglutinin associated with the receptor binding specificity of influenza viruses: 2009 H1N1, avian H5N1, and swine H1N2. Journal of Biomedical Science and Engineering, 3, 114-123. doi:10.4236/ibise. 2010.32017

[10] $\mathrm{Hu}, \mathrm{W}$. (2010) Quantifying the effects of mutations on receptor binding specificity of influenza viruses. Journal of Biomedical Science and Engineering, 3, 227-240.

[11] $\mathrm{Hu}, \mathrm{W}$. (2010) Highly conserved domains in hemagglutinin of influenza viruses characterizing dual receptor binding. Natural Science, 2, 1005-1014. doi:10.4236/ns.2009.29123

[12] Veljko, V., Henry, L.N., Sanja, G., Nevena, V., Vladimir, P. and Claude, P.M. (2009) Identification of hemagglutinin structural domain and polymorphisms which may modulate swine H1N1 interactions with human receptor. BMC Structural Biology, 9, 62. doi:10.1186/1472-6807-9-62

[13] Veljkovic, V., Veljkovic, N., Muller, C.P., Müller, S., Glisic, S., Perovic, V. and Köhler, H. (2009) Characterization of conserved properties of hemagglutinin of H5N1 and human influenza viruses: Possible consequences for therapy and infection control. BMC Structural Biology, 7, 9-21.

[14] Hu, W. (2009) Analysis of correlated mutations, stalk motifs, and phylogenetic relationship of the 2009 influenza a virus neuraminidase sequences. Journal of Biomedical Science and Engineering, 2, 550-558.

[15] $\mathrm{Hu}, \mathrm{W}$. (2010) The interaction between the $2009 \mathrm{H} 1 \mathrm{~N} 1$ influenza a hemagglutinin and neuraminidase: Mutations, co-mutations, and the NA stalk motifs. Journal of Biomedical Science and Engineering, 3, 1-12. doi:10.4236/jbise.2010.31001

[16] Chen, G.-W., Chang, S.-C., Mok, C.-K., Lo, Y.-L., Kung, Y.-N., et al. (2006) Genomic signatures of human versus avian influenza a viruses. Emerging Infectious Diseases, 12, 1353-1360.

[17] Chen, G.-W. and Shih, S.-R. (2009) Genomic signatures of influenza a pandemic (H1N1) 2009, virus. Emerging Infectious Diseases, 15, 1897-1903.

[18] Pan, C., Cheung, B., Tan, S., Li, C., Li, L., et al. (2010) Genomic signature and mutation trend analysis of pandemic (H1N1) 2009, influenza A virus. PLoS ONE, 5, Article ID e9549. doi:10.1371/journal.pone.0009549

[19] Miotto, O., Heiny, A., Tan, T.W., August, J.T. and Brusic, V. (2008) Identification of human-to-human transmissibility factors in PB2 proteins of influenza A by large-scale mutual information analysis. BMC Bioinformatics, 9, S18. doi:10.1186/1471-2105-9-S1-S18

[20] Miotto, O., Heiny, A.T., Albrecht, R., García-Sastre, A., Tan, T.W., August, J.T. and Brusic, V. (2010) Completeproteome mapping of human influenza A adaptive mutations: Implications for human transmissibility of zoonotic strains. PLoS ONE, 5, Article ID e9025. doi:10.1371/journal.pone.0009025

[21] Finkelstein, D.B., Mukatira, S., Mehta, P.K., Obenauer, J.C., Su, X., Webster, R.G. and Naeve, C.W. (2007) Persistent host markers in pandemic and H5N1 influenza viruses. Journal of Virology, 81, 10292-10299. doi:10.1128/JVI.00921-07 
[22] Allen, J.E., Gardner, S.N., Vitalis, E.A. and Slezak, T.R. (2009) Conserved amino acid markers from past influenza pandemic strains. BMC Microbiology, 9, 77. doi:10.1186/1471-2180-9-77

[23] Breiman, L. (2001) Random forests. Machine Learning, 45, 5-32. doi:10.1023/A:1010933404324

[24] Hu, W. (2010) Novel host markers in the 2009 pandemic H1N1 influenza A virus. Journal of Biomedical Science and Engineering, 3, 584-601.

[25] Hu, W. (2010) Nucleotide host markers in the influenza A viruses. Journal of Biomedical Science and Engineering, 3, 684-699.

[26] Katoh, K., Kuma, K., Toh, H. and Miyata, T. (2005) MAFFT version 5: Improvement in accuracy of multiple sequence alignment. Nucleic Acids Research, 33, 511518. doi:10.1093/nar/gki198

[27] Cosic, I. (1997) The Resonant Recognition Model of Macromolecular Bioreactivity, Theory and Application. Birkhauser Verlag, Berlin.

[28] Hu, W. (2011) Receptor binding specificity and origin of 2009 H1N1 pandemic influenza virus. Natural Science, 3, 234-248.

[29] Cover, T.A. and Thomas, J.A. (1991) Elements of Information Theory. John Wiley and Sons, New York. doi:10.1002/0471200611

[30] MacKay, D. (2003) Information Theory, Inference, and Learning Algorithms. Cambridge University Press, Cambridge.

[31] Bogs, J., Veits, J., Gohrbandt, S., Hundt, J., Stech, O., et al. (2010) Highly pathogenic H5N1 influenza viruses carry virulence determinants beyond the polybasic hemagglutinin cleavage site. PLoS ONE, 5, Article ID e11826. doi:10.1371/journal.pone.0011826

[32] Gohrbandt, S., Veits, J., Hundt, J., Bogs, J., Breithaupt, A., Teifke, J.P., Weber, S., Mettenleiter, T.C. and Stech, J. (2011) Amino acids adjacent to the haemagglutinin cleavage site are relevant for virulence of avian influenza viruses of subtype H5. Journal of General Virology, 92, 51-59. doi:10.1099/vir.0.023887-0

[33] Stevens, J., Blixt, O., Tumpey, T.M., Taubenberger, J.K., Paulson, J.C. and Wilson, I.A. (2006) Structure and receptor specificity of the hemagglutinin from an $\mathrm{H} 5 \mathrm{~N} 1$ influenza virus. Science, 312, 404-410. doi:10.1126/science. 1124513

[34] Wang, W., Lu, B., Zhou, H., Suguitan, A.L. Jr., Cheng, X., Subbarao, K., Kemble, G. and Jin, H. (2010) Glycosylation at $158 \mathrm{~N}$ of the hemagglutinin protein and receptor binding specificity synergistically affect the antigenicity and immunogenicity of a live attenuated H5N1 A/Vietnam/1203/2004 vaccine virus in ferrets. Journal of Virology, 84, 6570-6577. doi:10.1128/JVI.00221-10

[35] Auewarakul, P., Suptawiwat, O., Kongchanagul, A., et al. (2007) An avian influenza H5N1 virus that binds to a human-type receptor. Journal of Virology, 81, 9950-9955. doi:10.1128/JVI.00468-07

[36] Yamada, S., Suzuki, Y., Suzuki, T., Le, M.Q., Nidom, C.A., et al. (2006) Haemagglutinin mutations responsible for the binding of $\mathrm{H} 5 \mathrm{~N} 1$ influenza A viruses to humantype receptors. Nature, 444, 378-382. doi:10.1038/nature 05264

[37] Neumann, G., Chen, H., Gao, G.F., Shu, Y.-L. and
Kawaoka, Y. (2010) H5N1 influenza viruses: Outbreaks and biological properties. Cell Research, 20, 51-61. doi:10.1038/cr.2009.124

[38] Ayora-Talavera, G., Shelton, H., Scull, M.A., Ren, J., Jones, I.M., et al. (2009) Mutations in H5N1 influenza virus hemagglutinin that confer binding to human tracheal airway epithelium. PLOS ONE, 4, Article ID e7836. doi:10.1371/journal.pone.0007836

[39] Gambaryan, A., Tuzikov, A., Pazynina, G., Bovin, N., Balish, A. and Klimov, A. (2006) Evolution of the receptor binding phenotype of influenza a (H5) viruses. Virology, 344, 432-438. doi:10.1016/j.virol.2005.08.035

[40] Scalera, N.M. and Mossad, S.B. (2009) The first pandemic of the 21st century: A review of the 2009 pan-demic variant influenza a (H1N1) virus. Postgraduate Medicine, 121, 43-47. doi:10.3810/pgm.2009.09.2051

[41] Maurer-Stroh, S., Lee, R.T., Eisenhaber, F., Cui, L., Phuah, S.P. and Lin, R.T. (2010) A new common mutation in the hemagglutinin of the 2009 (H1N1) influenza A virus. PLoS Currents Influenza, 1, 162. doi:10.1371/currents.RRN1162

[42] Barr, I.G., Cui, L., Komadina, N., Lee, R.T., Lin, R.T., Deng, Y., Caldwell, N., Shaw, R. and Maurer-Stroh, S. (2010) A new pandemic influenza A(H1N1) genetic variant predominated in the winter 2010 influenza season in Australia, New Zealand and Singapore. Euro Surveill, 15, 19692.

[43] Stevens, J., Blixt, O., Chen, L.M., Donis, R.O., Paulson, J.C. and Wilson, I.A. (2008) Recent avian H5N1 viruses exhibit increased propensity for acquiring human receptor specificity. Journal of Molecular Biology, 381, 13821394. doi:10.1016/j.jmb.2008.04.016

[44] Fereidouni, S.R., Beer, M., Vahlenkamp, T. and Starick, E. (2009) Differentiation of two distinct clusters among currently circulating influenza $\mathrm{A}(\mathrm{H} 1 \mathrm{~N} 1)$ viruses. Euro Surveill, 14, 19409.

[45] $\mathrm{Hu}, \mathrm{W}$. (2010) Subtle differences in receptor binding specificity and gene sequences of the 2009 pandemic $\mathrm{H} 1 \mathrm{~N} 1$ influenza virus. Advances in Bioscience and Biotechnology, 1, 305-314. doi:10.4236/abb.2010.14040

[46] Hu, W. (2011) New mutational trends in the HA protein of $2009 \mathrm{H} 1 \mathrm{~N} 1$ pandemic influenza virus from May 2010 to February 2011. Natural Science, 3, 379-387.

[47] Long, J.X., Peng, D.X., Liu, Y.L., Wu, Y.T. and Liu, X.F. (2008) Virulence of H5N1 avian influenza virus enhanced by a 15-nucleotide deletion in the viral nonstructural gene. Virus Genes, 36, 471-478. doi:10.1007/s11262-007-0187-8

[48] Hatta, M., Hatta, Y., Kim, J.H., Watanabe, S., Shinya, K., et al. (2007) Growth of H5N1 influenza a viruses in the upper respiratory tracts of mice. PLoS Pathog, 3, Article ID e133. doi:10.1371/journal.ppat.0030133

[49] Sung, J.C., van Wynsberghe A.W., Amaro, R.E., Li, W.W. and McCammon, J.A. (2010) Role of secondary sialic acid binding sites in influenza N1 neuraminidase. Journal of the American Chemical Society, 132, 28832885. doi:10.1021/ja9073672

[50] Hu, W. (2010) Host markers and correlated mutations in the overlapping genes of influenza viruses: M1, M2; NS1, NS2; and PB1, PB1-F2. Natural Science, 2, 1225-1246. doi:10.4236/ns.2010.211150 
[51] $\mathrm{Hu}, \mathrm{W}$. (2010) Correlated mutations in the four influenza proteins essential for viral RNA synthesis, host adaptation, and virulence: NP, PA, PB1, and PB2.
Natural Science, 2, 1138-1147.

doi:10.4236/ns.2010.210141 